\begin{tabular}{|c|c|c|}
\hline 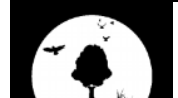 & Dur & $\begin{array}{l}\text { ISSN: 1991-2951 (Print) } \\
\text { ISSN: 2091-2781 (Online) }\end{array}$ \\
\hline $\begin{array}{l}\text { Nature Conservation \& } \\
\text { Health Care Council } \\
\text { Biratnogar Nopal }\end{array}$ & & \\
\hline
\end{tabular}

\title{
ELISA validation and determination of cut-off level for chloramphenicol (CAP) residues in shrimp and fish
}

\author{
Md. Golam Sarwer1,2*, Md. Mahmudul Hasan Rony ${ }^{1}$, MSt. S. Sharmin³, \\ A.K. Jilani Chowdhury ${ }^{2}$ and Shuva Bhowmik ${ }^{2}$ \\ ${ }^{1}$ Fish Inspection and Quality Control (FIQC) Office, Chittagong, Bangladesh \\ ${ }^{2}$ Faculty of Fisheries, Bangladesh Agricultural University, Mymensingh, Bangladesh \\ ${ }^{3}$ Bangladesh Fisheries Research Institute (BFRI), Mymensingh, Bangladesh \\ *E-mail: sarwerfiqc@gmail.com
}

\begin{abstract}
An analytical validation of enzyme-linked immunosorbent assay (ELISA) screening for detection of chloramphenicol (CAP) in shrimp and fish was conducted according to the Commission Decision 2002/657/EC and guidelines for the validation of screening methods for residues of veterinary medicines. The analyte was extracted from shrimp and fish with ethyl acetate mixture, and CAP concentrations were measured photometrically at $450 \mathrm{~nm}$. The recovery rate of the analyte from spiked samples was $80 \%$. For the laboratory the cut-off level of CAP in fish and shrimp as the minimum recovery was established along with detection capability $(C C \beta)$. No relevant interferences between matrix effects and structurally related substances including florfenicol and thiamphenicol were observed. The experimental results were quite satisfactory and ELISA method was found very useful for determination of CAP residues in shrimp and fish monitoring.
\end{abstract}

Key words: CC $\beta$, Photometry, Analyte sample, Fish monitoring

DOI: http://dx.doi.org/10.3126/on.v15i1-2.18789
Manuscript details: Received: 01.06.2017 / Accepted: 07.11.2017
Citation: Sarwer, Md. G., Md. M.H. Rony, MSt. S. Sharmin, A.K.J. Chowdhury and S. Bhowmik 2017. ELISA validation and
determination of cut-off level for chloramphenicol (CAP) residues in shrimp and fish. Our Nature 15(1-2): 13-18. DOI:
http://dx.doi.org/10.3126/on.v15i1-2.18789
Copyright: () Sarwer et al., 2017. Creative Commons Attribution - Non Commercial 4.0 International License.

\section{Introduction}

Chloramphenicol $\left(\mathrm{C}_{11} \mathrm{H}_{12} \mathrm{C}_{12} \mathrm{~N}_{2} \mathrm{O}_{5}\right)$ was synthesized from the bacterium Streptomyces venezuelae by David Gotlieb in 1947 (Pattarawarapan et al., 2006). This antibiotic is active against a wide range of aerobic and anaerobic bacteria and fungi. Application of chloramphenicol in reared animals is raising serious concerns due to its bioaccumulation in tissues. Presence of anti-microbial drug residues in the edible tissues can cause allergies, toxic effects, alteration in the intestinal microbial fauna and acquisition of drug-resistance. Residues of chloramphenicol in food consumed by humans can even result in a plastic anemia, which leads to very serious bone marrow diseases and a syndrome of cyanosis and cardiovascular collapse known as "grey syndrome" may also occur, particularly in neonates (Impens et al., 2003).

In aquaculture, antibiotics have been used mainly for therapeutic purposes and as prophylactic agents. Shrimp and fish culture is facing serious hurdles among which the disease outburst caused by microbes is a severe havoc. Infective diseases are always a hazard, and may cause major stock losses and problems of animal welfare. To control infectious diseases in 
aquaculture, antibiotics are used. As there are no antibiotics specifically designed for aquaculture, authorized products developed for other areas of veterinary medicines like chloramphenicol, tetracycline, florfenicol, thiamphenicol, furazolidone, nitrofurazone etc. are applied to curtail microbial attacks (Shen and Jiang, 2005). Among these, chloramphenicol is commonly used in hatchery conditions as it exhibits broad spectrum activity over various microorganisms. World Health Organization (WHO) have already raised the issue of irresponsible use of antibiotics in all food production sectors, with particular concern for the potential risks to human health and hence the application of chloramphenicol in food is banned. Countries like Europe and USA have restricted the importing of chloramphenicol residue food stuffs due to its toxic side effects (Shen and Jiang, 2005). Several analytical methods are employed in the quantitative detection of chloramphenicol in seafood's by using swab tests, instrumental methods (HPLC and GC-MS) and immunoassays (RIA, CLIA, ELISA, etc.) (Impens et al., 2003). Chromatographic techniques such as GC and HPLC offer great sensitivity of the detection. These techniques were more laborious and require highly specialized technicians and expensive instruments.

Today the chloramphenicol residues can microbial, enzymatic and immunological assays (Nagata and Saeki, 1992; Kolosova et al., 2000; Pfenning et al., 2000; Pfenning et al., 2002; Riet et al., 2003). ELISA detection of chloramphenicol is highly specific and precise, quick, easy to handle, even the limit of detection is susceptible and allows the analysis of high volumes of samples within a short time. In this backdrop, an attempt has been made in the present study to unravel the level of chloramphenicol residues in the tissues of shrimps and fishes using competitive ELISA kit. Hence the feasibility of using the ELISA method for testing shrimp and fish tissues was investigated. The method has been validated according to the criteria of the 2002/657/EC Decision.

\section{Materials and methods}

\section{ELISA kit}

An ELISA Chloramphenicol kit (Catalogue no. CN 1469) was purchased from Randox, UK. The test kit contained: a 96 well microtitre plate coated with capture antibodies against chloramphenicol antibodies; six chloramphenicol standards at concentrations of $0.00,0.10,0.25$, $0.50,1.00,5.00 \mathrm{ng} \mathrm{ml}^{-1}$; a bottle of peroxides' conjugated chloramphenicol concentrate; a bottle of substrate/chromogen solution; a bottle of stop solution $1 \mathrm{~N}$ sulphuric acid; wash buffer for conjugate dilution and plate wash.

\section{Standard solutions}

Chloramphenicol, florfenicol and thiamphenicol standards were purchased from Sigma-Aldrich sourced as pure drugs with a certificate of analysis. Stock solution of $100 \mathrm{ng} \mathrm{ml}^{-1}$ was prepared from the three standards using methanol as a solvent. A working standard solution $\left(10 \mathrm{ng} \mathrm{ml}^{-1}\right)$ was prepared before each analysis from the chloramphenicol stock solution diluted with the buffer provided with the test kit.

\section{Spiked samples}

For the fortified sample, twenty-four sets (12 sets shrimp samples and 12 sets fish samples) of different species from different locations were used. The samples were obtained from firms and natural sources involved in the national residue program. They were spiked with $10 \mathrm{ng} \mathrm{ml}^{-1}$ of working chloramphenicol standard solution at the screening target concentration (STC) of 0.15 $\mu \mathrm{g} \mathrm{kg}{ }^{-1}$. The fortified samples were left for 30 min before the analysis.

\section{Sample preparation}

A three gram of fish and shrimp samples were placed into $50 \mathrm{ml}$ reaction tubes. A $6 \mathrm{ml}$ of ethyl acetate was added and homogenized for one minute with a vortex mixture. The tube was then centrifuged at $2000 \mathrm{rpm}$ for $15 \mathrm{~min}$. After centrifugation the supernatant was discarded and the precipitate was dried with a stream of nitrogen on a hot plate at $70^{\circ} \mathrm{C}$. The dried residue was dissolved in $2 \mathrm{ml}$ of isooctane: chloroform (2:3) and vortex for one minute. After that $0.5 \mathrm{ml}$ diluted tissue extraction buffer provided with the ELISA kit was added and vortex for two minutes. Then centrifuge at 2000 rpm for $15 \mathrm{~min}$. A volume of $25 \mu 1$ well $^{-1}$ was used in the assay.

\section{ELISA procedure}

Each standard solution at the supplied concentrations mentioned above, blank solution and fortified samples were added to separate duplicate wells in a $25 \mu \mathrm{l}$ volume. A $100 \mu \mathrm{l}$ volume of diluted enzyme conjugate was added to the bottom of each well. After gentle manual mixing for a few seconds, the solutions were incubated for $60 \mathrm{~min}$ at 19 to $25^{\circ} \mathrm{C}$ in the dark. 
The non-bound enzyme-conjugate reagent was removed and washed 6 times with diluents/wash buffer over a 10-15 min period (ensuring that every well is filled). After final wash all the liquid was discarded and tap onto tissue paper until completely dry. The CAP enzyme conjugate amount was visualized by adding $125 \mu \mathrm{l}$ of one shot substrate/chromogen and incubated for $20 \mathrm{~min}$ in dark to transform it into a product colored by the bound enzyme conjugate. Stopping the substrate reaction was achieved by addition of stop buffer (1N sulphuric acid) provided with the kit followed by a color change from blue to yellow. The resulting color intensity was measured spectrophotometrically at $450 \mathrm{~nm}$ using a ELISA reader/micro plate reader (ELx 800, BioTek, USA).

\section{Validation}

The procedure was performed according to the Commission Decision (2002) and guidelines for the validation of screening methods for residues of veterinary medicines, community reference laboratories residues (CRLs) 20/1/2010 (Water et al., 1987). The performance characteristics including the specificity/selectivity, detection capabilities of $C C \beta$ and cut-off level were determined. The selectivity and specificity were evaluated by analyzing blank shrimp and fish samples fortified with thiamphenicol and florfenicol (chemically related to CAP) at the concentration corresponding to the MRL.

\section{Results and discussion}

\section{Chloramphenicol in shrimp and fish samples}

The quantitative analysis by the enzyme immunoassay of chloramphenicol was validated by the determination of specificity/selectivity, detection capabilities of $C C \beta$, cut-off level and stability of analyte. The cut-off level is the response or signal in a screening test which indicates that a sample contains a substance at concentration similar to or higher than the screening target concentration (STC) and specifies the concentration at which a screening test categorizes the samples as potentially noncompliant and needing confirmatory analysis. During the validation process, the cut-off level was established using the matrix blank sample analysis and replicates of the same samples spiked (fortified) at the STC. For chloramphenicol in fish and shrimp matrix blank samples have been spiked in order to establish the Cut-
Off level at half of the regulatory limit. A minimum required performance limit (MRPL) for chloramphenicol is $0.3 \mu \mathrm{g} \mathrm{kg}^{-1}$, so screening target concentration (STC) is set at $0.15 \mu \mathrm{g} \mathrm{kg}^{-1}$. The cut-off level for shrimp and fish matrix was calculated at a concentration of $0.082 \mu \mathrm{g} \mathrm{kg}^{-1}$ (Table 1). Blank and spiked samples were analyzed in different periods. The analysis also included the range of response in the blank samples. The highest response of the blank samples was noted as $0.028 \mu \mathrm{g} \mathrm{kg}^{-1}$ and the lowest response in the spiked samples was noted as $0.082 \mu \mathrm{g} \mathrm{kg}^{-1}$. In this case shown, none of the responses of the spiked samples overlaps with the range of responses of the blank samples. For this reason, the $C C \beta$ was established to be less than or equal to $0.15 \mu \mathrm{g} \mathrm{kg}^{-1}$. Consequently, the $C C \beta$ of this assay and the $\beta$ error were $0.15 \mu \mathrm{g}$ $\mathrm{kg}^{-1}$ and 0 respectively. This meets the condition laid down in commission decision 2002/657/EC which permits less than $5 \%$ of false compliant results $(\beta$ error).

Table 1. Response of negative samples and spiked samples of CAP in Shrimps and Fishes.

\begin{tabular}{|c|c|c|}
\hline $\begin{array}{l}\text { Sample } \\
\text { No. }\end{array}$ & $\begin{array}{c}\begin{array}{c}\text { Negative Sample ( } \mu \mathrm{g} \\
\left.\mathrm{kg}^{-1}\right)^{*}\end{array} \\
\end{array}$ & $\begin{array}{c}\text { Spike @ } 0.15 \\
\mu \mathrm{g} \mathrm{kg} \mathrm{kg}^{-1}\end{array}$ \\
\hline 1 & 0.000 & 0.122 \\
\hline 2 & 0.004 & 0.113 \\
\hline 3 & 0.000 & 0.122 \\
\hline 4 & 0.000 & 0.133 \\
\hline 5 & 0.000 & 0.100 \\
\hline 6 & 0.000 & 0.101 \\
\hline 7 & 0.000 & 0.096 \\
\hline 8 & 0.006 & 0.087 \\
\hline 9 & 0.026 & 0.139 \\
\hline 10 & 0.014 & 0.124 \\
\hline 11 & 0.017 & 0.161 \\
\hline 12 & 0.025 & 0.168 \\
\hline 13 & 0.028 & 0.155 \\
\hline 14 & 0.023 & 0.181 \\
\hline 15 & 0.024 & 0.161 \\
\hline 16 & 0.009 & 0.082 \\
\hline 17 & 0.009 & 0.106 \\
\hline 18 & 0.006 & 0.111 \\
\hline 19 & 0.007 & 0.106 \\
\hline 20 & 0.003 & 0.106 \\
\hline 21 & 0.000 & 0.122 \\
\hline 22 & 0.001 & 0.113 \\
\hline 23 & 0.002 & 0.091 \\
\hline 24 & 0.003 & 0.086 \\
\hline
\end{tabular}

It was observed that the lowest response of spike sample was 0.082 . Therefore, the Cut-Off Level of this test is $0.082 \mu \mathrm{g} \mathrm{kg}^{-1}$. Any sample giving a response greater than this level is deemed to be a 'screen positive' and exceeds the 
$C C \beta$ of the screening method. The average recovery of this test was $80 \%$ and reproducibility precision (CV) was $23 \%$. Shen and Jiang (2005) detected chloramphenicol residues at the levels of $0.1-10 \mu \mathrm{g} \mathrm{kg}^{-1}$ using ELISA, HPLC, GC-ECD, GC_MS_EI_SIM methods (Takino et al., 2003). Impens et al. (2003) used GC-MS/MS method for determination of chloramphenicol, in which the detection limit was $0.1 \mu \mathrm{g} \mathrm{kg}^{-1}$ and Storey et al. (2003) estimated chloramphenicol from shrimp tissue by using LCMS/MS and limit of detection was $0.1 \mu \mathrm{g} \mathrm{kg}^{-1}$. Pattarawarapan et al. (2006) used competitive ELISA for detection of chloramphenicol and the detection range was 10$1280 \mathrm{ng} \mathrm{ml}^{-1}$. The detection range of these techniques varies from each other but screening is the ultimate base of all the studies.

Competitive ELISA is an easier way to screen for the seafood samples containing chloram-phenicol, which is highly specific and precise, quick, easy to handle, even the limit of detection is susceptible and allows the analysis of high volumes of samples within a short time.

\section{Determining Cut-Off Levels and CCB in a semi- quantitative screening test}

According to the Commission Decision 2002 $1657 / \mathrm{EC}$, the detection capability is validated when, Fm > B. Also the laboratory has to determine the rate of false positive (FP) which is acceptable with the method. Here the conditions are If $\mathrm{B}<\mathrm{Fm}<\mathrm{T}$ and the $\mathrm{FP}$ is higher than $5 \%$. In case of $\mathrm{Fm}>\mathrm{T}$, the rate of FP is below 5\% (Table 2). To check the above mention relation (criteria), Threshold value $\mathrm{T}$, is calculated using the following formula:

Threshold value $\mathrm{T}=\mathrm{B}+1.64 * \mathrm{SD}_{\mathrm{b}}$

Where, $\mathrm{B}=$ mean blank conc., $\mathrm{SD}_{\mathrm{b}}=$ standard deviation of blank

Here, $\mathrm{B}=0.008625$ and $\mathrm{SD}_{\mathrm{b}}=0.009805999$ have been calculated from the data.

Therefore, Threshold value $\mathrm{T}=0.024707$

Cut-off factor Fm, is also calculated using the following formula for ELISA Ref: (CRLs Guidelines):

Cut-off factor $\mathrm{F}_{\mathrm{m}}=\mathrm{M}+1.64 * \mathrm{SD}$

Where, $\mathrm{M}=$ mean spike conc., $\mathrm{SD}=$ standard deviation of spike.

Here, $\mathrm{M}=0.12025$ and $\mathrm{SD}=0.02782125$ as calculated from the data

Then, Cut-off factor $F_{m}=0.165877$

Table 2. Relative response (\%) for comparison between blank and spike samples.

\begin{tabular}{ccccc}
\hline \multirow{2}{*}{ Repetitions } & \multicolumn{4}{c}{ Response \% } \\
\cline { 2 - 5 } & $\begin{array}{c}\text { Mean } \\
\text { Spike }\end{array}$ & $\begin{array}{c}\text { Spike } \\
\text { sample }\end{array}$ & $\begin{array}{c}\text { Mean } \\
\text { blank }\end{array}$ & $\begin{array}{c}\text { Blank } \\
\text { sample }\end{array}$ \\
\hline 1 & 100 & 101.455 & 7.173 & 0.000 \\
2 & 100 & 93.971 & 7.173 & 3.326 \\
3 & 100 & 101.455 & 7.173 & 0.000 \\
4 & 100 & 110.603 & 7.173 & 0.000 \\
5 & 100 & 83.160 & 7.173 & 0.000 \\
6 & 100 & 83.992 & 7.173 & 0.000 \\
7 & 100 & 79.834 & 7.173 & 0.000 \\
8 & 100 & 72.349 & 7.173 & 4.990 \\
9 & 100 & 115.593 & 7.173 & 21.622 \\
10 & 100 & 103.119 & 7.173 & 11.642 \\
11 & 100 & 133.888 & 7.173 & 14.137 \\
12 & 100 & 139.709 & 7.173 & 20.790 \\
13 & 100 & 128.898 & 7.173 & 23.285 \\
14 & 100 & 150.520 & 7.173 & 19.127 \\
15 & 100 & 133.888 & 7.173 & 19.958 \\
16 & 100 & 68.191 & 7.173 & 7.484 \\
17 & 100 & 88.150 & 7.173 & 7.484 \\
18 & 100 & 92.308 & 7.173 & 4.990 \\
19 & 100 & 88.150 & 7.173 & 5.821 \\
20 & 100 & 88.150 & 7.173 & 2.495 \\
21 & 100 & 101.455 & 7.173 & 0.000 \\
22 & 100 & 93.971 & 7.173 & 0.832 \\
23 & 100 & 75.676 & 7.173 & 1.663 \\
24 & 100 & 71.518 & 7.173 & 2.495 \\
\hline & & & &
\end{tabular}

In this case, detection capability has been validated because $F_{m}>B$ and $F_{m}>T$, so the rate of false positive is below 5\% (Fig. 1), none of the responses of the spiked samples overlaps with the range of responses of the blank samples. For this reason, the $C C \beta$ was established to be less than or equal to $0.15 \mu \mathrm{g} \mathrm{kg}^{-1}$.

\section{Stability of analyte}

The stability of analyte in standard solution was determined and declared by the kit manufacturer. For stability of analyte in matrix extract, two blank samples (one fish and one shrimp) were taken and homogenized. Samples were fortified with $0.15 \mathrm{ppb}$ of chloramphenicol. Fortified samples were extracted following the kit manual. Extract was divided into 6 aliquots (3 fish and 3 shrimps). Analysis of one aliquot of fish was carried out immediately. The remaining 2 aliquots were preserved at $-20^{\circ} \mathrm{C}$ and analyzed one by one on following 2 days. Same steps were repeated with 3 shrimp aliquots. 


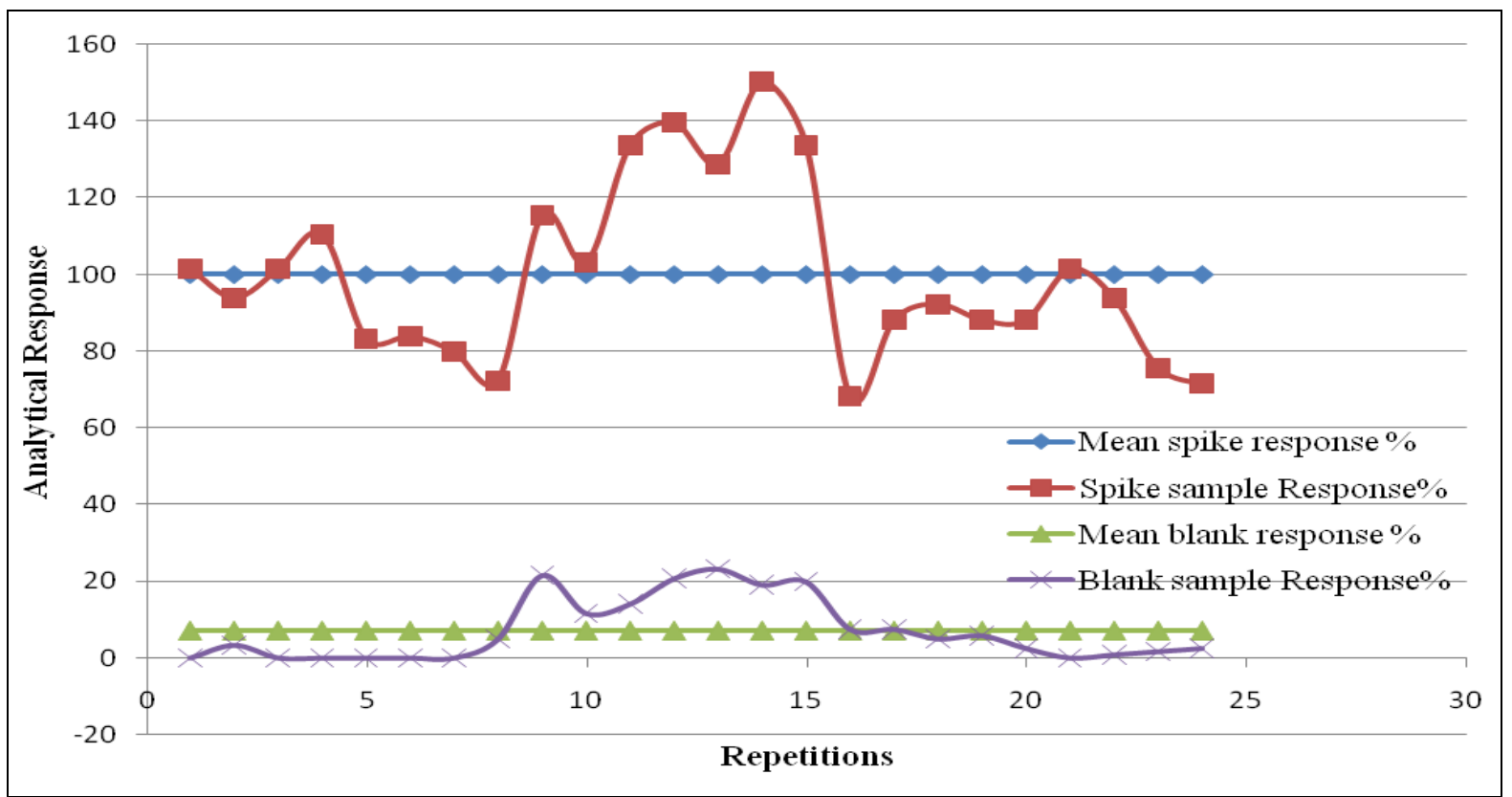

Figure 1. The blank sample response to spike samples.

The calculation of the concentration of the analyte in each aliquot carried out by using the solution of the analyte freshly prepared at the time of analysis as $100 \%$.

Analyte remaining $(\%)=\mathrm{C}_{\mathrm{i}} \times 100 / \mathrm{C}_{\text {fresh }}$

Where, $\mathrm{C}_{\mathrm{i}}=$ concentration at time point, $\mathrm{C}_{\mathrm{fresh}}=$ concentration of fresh solution.

Analyte in matrix extract is almost stable with time (up to 3 days) (Table 3 ). during the extraction of CAP residues in order to reduce unspecific binding and lower the $C C \beta$ and the LOD. Consequently, the method is suitable for detecting chloramphenicol in shrimp and fish and may be used for screening purposes connected with the national residue programme. It may be necessary to validation of the CAP ELISA method in order to harmonize the analytical performance of method.

Table 3. Stability of analyte in matrix extract

\begin{tabular}{|c|c|c|c|c|c|c|c|}
\hline & $\begin{array}{c}\text { Spike conc. } \\
\left(\mu \mathrm{g} \mathrm{kg}^{-1}\right)\end{array}$ & $\begin{array}{c}\text { No. of } \\
\text { analysis }\end{array}$ & $\begin{array}{c}\text { Cfresh } \\
\left(\mu \mathrm{g} \mathrm{kg}^{-1}\right) \\
\end{array}$ & $\begin{array}{c}\text { Mean Cfresh } \\
\left(\mu \mathrm{g} \mathrm{kg}^{-1}\right)\end{array}$ & $\begin{array}{c}\mathbf{C i} \\
\left(\mu \mathrm{g} \mathrm{kg}^{-1}\right) \\
\end{array}$ & $\begin{array}{l}\text { Mean Ci } \\
\left.\left(\mu g^{-1}\right)^{-1}\right) \\
\end{array}$ & $\begin{array}{c}\text { Analyte } \\
\text { remaining \% }\end{array}$ \\
\hline \multirow[t]{2}{*}{$\overline{\text { Day-1 }}$} & $0.15(1 / 2$ & 1 & 0.122 & 0.111 & 0.122 & 0.111 & 100.000 \\
\hline & MRPL) & 2 & 0.1 & & 0.1 & & \\
\hline \multirow[t]{2}{*}{ Day-2 } & $0.15(1 / 2$ & 1 & 0.122 & 0.111 & 0.111 & 0.119 & 106.757 \\
\hline & MRPL) & 2 & 0.1 & & 0.126 & & \\
\hline \multirow[t]{2}{*}{ Day-3 } & $0.15(1 / 2$ & 1 & 0.122 & 0.111 & 0.101 & 0.103 & 92.793 \\
\hline & MRPL) & 2 & 0.1 & & 0.105 & & \\
\hline
\end{tabular}

The selectivity/specificity data indicated that no relevant matrix interferences were observed during the validation. Moreover, no interference was found when the thiamphenicol and florfenicol were added to samples at the MRL concentration. The antibodies directed against chloramphenicol did not show cross-reactivity with other phenicols, indicating that the monoclonal antibodies used in the test were highly specific to CAP.

\section{Conclusion}

The present study showed that the sensitivity of CAP ELISA validated for tissues can be improved further by thorough cleaning of tissues

\section{Acknowledgements}

We wish to acknowledge the efforts of all lab personnel in Quality Control laboratory (Microbiology and Chemistry Unit). We also acknowledge support from Md. Shahjahan Ali, Quality Assurance Manager of Chittagong Quality Control laboratory. Special gratitude goes to Provati Deb, Deputy Director of Chittagong Fish Inspection office for her cooperative help.

\section{References}

Commission Decision 2002. Commission decision 2002/657/EC of $12^{\text {th }}$ August, 2002. Implementing Council Directive 96/23/EC concerning the 
performance of analytical methods and the interpretation of results. O.J. 221: 8-36.

Impens, S., W. Reybroeck, J. Vercammen, D. Courtheyn, S. Ooghe, K.D. Wasch, W. Smedts and H.D. Brabander 2003. Screening and confirmation of chloramphenicol in shrimp tissue using ELISA in combination with GCMS2 and LCMS2. Ana Chim Acta. 483: 153-63.

Kolosova, A.Y., J.V. Samsonova and A.M. Egorov 2000. Competitive ELISA of chloramphenicol: influence of immuno reagent structure and application of the method for the inspection of food and animal origin. Food and Agri Immunol. 12: 115-125.

Nagata, T. and M. Saeki 1992. Simultaneous determination of thiamphenicol, florfenicol and chloramphenicol residues in muscles of animals and cultured fish by liquid chromatography. $J$. Liq. Chromatogr. 15: 2045-2056.

Pattarawarapan M, Nangola S and Tayapiwatana C. 2006. Establishment of competitive ELISA for detection of chloramphenicol. Chiang Mai J Sci. 33(1): 85-94.

Pfenning, A., S. Turnipseed, J. Roybal, M. Madson, R. Lee and J. Storey 2002. Confirmed chloramphenicol residue in crab by electrospray. Laboratory Information Bulletin No. 4294.

Pfenning, A.P., J.E. Roybal, H.S. Rupp, S.B. Turnipseed, S.A. Gonzales and J.A. Hurlbut 2000. Simultaneous determination of residues of chloramphenicol, florfenicol, florfenicol amine and thiamphenicol in shrimp tissue by gas chromatography with electron capture detection. J. AOAC Int. 83: 26-30.

Riet, J.M., R.A. Potter, M. Christie-fougere and G. Burnsb 2003. Simultaneous determination of residues of chloramphenicol, thiamphenicol, florfenicol, andflorfenicol amine in farmed aquatic species by liquid, chromatography/mass spectrometry. J. AOAC Int. 86: 510.

Shen, H.Y. and H.L. Jiang 2005. Screening, determination and confirmation of chloramphenicol in seafood, meat and honey using ELISA, HPLC-UVD, GC-ECD, GCMS-EI-SIM and GCMS-NCI- SIM methods. Analytica Chimica Acta. 53(5): 33-41.

Storey, J., A. Pfenning, S. Turnipseed, G. Nandrea, R. Lee, C. Burns and M. Madson 2003. Determination of chloramphenicol residues in shrimp and crab tissues by electrospray triple quadrupole LC/MS/MS. U.S. FDA. Laboratory Information Bulletin No. 4306.

Takino, M.S., K. Daishima and T. Nakanara 2003. Determination of chloramphenicol residues in fish meats by liquid chromatography atmospheric pressure photoionization mass spectrometry. J. Chrom. 10(11): 67-75.

Water, C.V.D., N. Haagsma, V.P.J. Kooten and V.W. Eden 1987. An enzyme linked immunosorbent assay for the determination of chloramphenicol using a monoclonal antibody. Application to residues in swine muscle tissue. Zei Leben Unter Fors. 18(5): 202-207. 